\title{
Community capacity building approaches and sustainability of health care projects: Implications from palliative care projects in Mayuge district in Uganda
}

\author{
Barbara Komujuni ${ }^{1}$, Benon C Basheka ${ }^{2 \star}$ and Pross N. Oluka ${ }^{3}$ \\ ${ }^{1}$ Program officer for a USAID Health Care improvement Project which funded a palliative care project in Uganda. \\ ${ }^{2}$ Uganda Technology and Management University (UTAMU), Uganda. \\ ${ }^{3}$ Uganda Management Institute, Uganda.
}

Accepted 21 August, 2013

\begin{abstract}
The purpose of the study was to establish the extent to which community capacity building influenced sustainability of palliative care projects in Mayuge district. Specifically, the study strived to establish the extent to which top down, bottom up and community organizational approaches of capacity building could influence the sustainability of palliative care projects. We used a cross-sectional survey design to cover a population of 150 respondents comprising of NGO officials, Health centre IV and Health centre III palliative care personnel, district health team officials and patients on palliative care. Using a self administered questionnaire and in-depth interviews emerging data was analyzed using simple descriptive statistics like mean and standard deviations, Pearson's correlation and regression analyses. We report that top down organizational capacity building approach had a high positive significant relationship with project sustainability and it predicted $23.4 \%$ of the variance in project sustainability. Bottom up organisational capacity building approach had a high positive significant relationship and it predicted $25.7 \%$ of the variance in project sustainability. Finally, community organizing approaches had a very high positive significant relationship with project sustainability and it predicted $57.2 \%$ of the variance. We conclude that the financial, technical and managerial self reliance aspects of project sustainability are significantly dependant on the kind of efforts by the management teams of the NGO. By building capacity through top down, bottom up and community organizing approaches, there is a high possibility of ensuring sustainability. We therefore draw a number of managerial and theoretical implications whose scope appeals to a wide range of audiences.
\end{abstract}

Key words: Capacity building approaches, project, sustainability, palliative care.

\section{INTRODUCTION}

It has been widely acknowledged that insufficient capacity of development organizations hinders development project sustainability. This problem, however, cannot be defined simply in terms of gaps in human resources, financial resources, or training. The issue is a function of several aspects including excessive dependency of NGOs on external resources and technical assistance leading to limited sense of local ownership of the development processes, inadequate consideration of broader environmental or systems factors, poor integration and coordination of multiple development/ programme initiatives between different stakeholders such as government and private sector partners (Baillie, 2008; Deborah, 2005; Kaplan, 2000). Perhaps the most fundamental conceptualization of capacity building is that provided by Crisp et al. (2000) which highlight four 
distinct approaches to capacity building to include bottom up, top down, partnership and community organizing.

Top-down organizational approach states that building and sustaining capacity requires organizational capacity as well as the expertise of individuals (Grisso et al., 1995; Rist, 1995). Training programs must be facilitated within organizations through decision-making processes which ensure that staffs are able to participate. However, coordination and planning are often necessary to ensure resources, such as personnel, equipment and facilities can be mobilized when required (Poncelot and de Ville de Goyet, 1996). In some cases, increased capacity may be acquired through organizational restructuring. Bottom-up organizational approach is related to the development of technical expertise which is often considered to be essential for organizations (Chalmers, 1997; Crisp et al., 2000; Hawe et al., 2009), broadening the skills of generalist workers can also have strategic benefits. This approach according to Crisp et al. (2000) focuses on training members of the organization and providing them with skills and knowledge which is not only beneficial to the individuals concerned but more importantly to the organization and the wider community.

In partnerships, Chavis (1995) and Marty et al. (1996) noted that development of partnerships between organizations or groups of people who might otherwise have little or no working relationship is another approach to building capacity. This approach is based on the assumption that providing possibilities for the two-way flow of knowledge can lead to partnerships through which the resources required to plan and implement programs may emerge. This is especially so if prominent members of the community, including community leaders, community advocates and representatives, who can facilitate health promotion efforts, are involved (Wickizer et al., 1998). This study conceptualized capacity building as the top down organisational development, bottom up organisational development, development of partnerships, and community organizing.

Project sustainability refers to the capacity to maintain services and benefits both at the community and institution levels without detrimental effects even after special assistance such as financial, technical, managerial has been phased out (Cooper et al., 2005; Haddad et al., 2007). Based on the above conceptualization of project sustainability, this study conceptualized project sustainability as financial, technical and managerial self reliance of palliative care services in communities where the intervention has been undertaken by the donor intervention.

The period 1950s to 1960s is renowned for the capacity building movement focusing on enhancing the technological and self-help capacities of individuals in rural areas. In the 1970s, following a series of reports on international development an emphasis was put on building capacity for technical skills in rural areas, and also in the administrative sectors of developing countries (Smillie, 2001). By 1980s, the concept of institutional or organizational development expanded even more Institutional development was viewed as a long-term process of building up a developing country's government, public and private sector institutions, Non-Governmental Organizations (NGOs) and Community Based Organizations (CBOs) world over (Baillie, 2008). Deborah (2005) has ably demonstrated that though precursors to community capacity building existed before the 1990s, they were not powerful forces in International development. Capacity building as a leading developmental concept in the 1990s occurred due to a confluence of factors related to first, the new philosophies that promoted empowerment and participation, like Paulo Freire's "Education for critical consciousness" in 1973, which emphasized that education, could not be handed down from an omniscient teacher to an ignorant student rather it must be achieved through the process of a dialogue among equals.

Diane (2004) attributes capacity building developments in the 1980s on three assumptions: development is the process by which vulnerabilities are reduced and capacities increased, A third factor that contributed to the interest in capacity building then was the change in International Developmental approaches as seen in the 1980s where many low income states were subject to Structural Adjustment Programs (SAP) and the neoliberal nature of the packages leading to increasing disparities of wealth. In response, a series of social dimension adjustments were enacted. The growing wealth gap coupled with social dimension adjustments allowed for an increased significance for NGOs in developing states as they actively participated in social service delivery to the poor (Deborah, 2005).

Community development work in Uganda begun way back even before the coming of the Europeans after world war two. With the coming of Europeans, development took different paradigms which explain development through which programs and projects were started to champion development in communities (Uganda NGO Forum, 2008). To this effect, Capacity building was thought to be a means through which local population could be empowered to live sustainably. The major aspect of capacity building where many development practitioners have put emphasis is skills training through which people are given power to manage their own development even without external support. The government and none government organization, charity organizations in Uganda have done community empowerment through a series of trainings. In spite of such skills development, many development projects in the health sector have failed when direct funding phases out and left their survival at a great risk of collapsing (Uganda NGO Forum, 2008). For sustainability purposes, capacity building strategy ought to be built into the program design from inception and modalities for achieving it settled early 
in its life and not left to the final year of funding (Brown, 1997). This study therefore examined the influence of capacity building on the sustainability of health care projects in Uganda.

Community capacity building efforts of top down, bottom up and community organization approaches are widely used to achieve the desired financial, technical and managerial self reliance of most NGO interventions (Cooper, et al., 2005; Haddad et. al., 2007). Despite the use of capacity building approaches in most health care projects of Uganda, health care projects in Uganda seem to be constrained in achieving the desired sustainability. For example although palliative healthcare is intended to improve the quality of life of patients and families facing life-threatening illness through prevention and relief of suffering by early identification and treatment of pain and other physical, psychosocial and spiritual problems, only $2 \%$ of those who need palliative care services access them yet about $70 \%$ of those who happen to access the palliative care drop out from program for financial, technical and managerial constraints experienced by the palliative care project providers in Uganda (UNAIDS, 2010; Palliative care Association, 2010). This has had dare consequences on the achievement of the mandate of the palliative care projects in Uganda with most NGOs failing to provide the much needed palliative care after donors have withdrawn for failure to sustain their palliative care interventions. This study therefore strived to establish the influence of community capacity building approaches on the sustainability of palliative care projects in Uganda.

\section{THEORETICAL AND CONCEPTUAL FRAMEWORK}

The study was guided by the stakeholders' theory by Freeman (1984) and the Reeler (2006) social change underlying the Logical framework approach. The stakeholder's theory by Freeman (1984) identifies four major stakeholder groups to include shareholders, employees, customers, and the general public. Proponents of stakeholder's theory, assert that stakeholders are those groups without whose support the organization would cease to exist and it may equally mean any group or individual that can affect, or is affected by, the achievement of the organization's purpose. Freeman (1984) concluded by observing that managers must develop relationships, inspire their stakeholders, and create communities where everyone strives to give their best to deliver the value the organization promises. Certainly shareholders are an important constituent and profits are a critical feature of this activity, but concern for profits is the result rather than the driver in the process of value creation.

While building on this theory, Jones and Wicks (1999) put forward three forms of stakeholders' approaches namely descriptive, normative, and instrumental stake- holder approaches. The descriptive approach emphasizes understanding the relationship between an organization and its stakeholders while the normative approach emphasizes that organizations should take all stakeholders into consideration, as a moral responsibility. The instrumental perspective emphasizes that organizations should take key stakeholders into consideration as this leads to organizational success and competitive advantage. Chambers (1994) a later proponent of the stakeholders theory proposed the rapid rural appraisal (RRA) also termed participatory learning and action, emphasizes the need for understanding and addressing stakeholder needs in development by conducting interviews with stakeholders, drawing local maps or diagrams, and inviting solutions from the community itself to enable achievement of community development projects sustainability. From the afore discussed stakeholders theory and its practice, it is evident that the theory proposes project stakeholders' involvement, beneficiaries capacity building and project sustainability that are to be used in this study.

The Reeler (2006) theory of social change underlying the Logical framework approach assumes that project interventions themselves introduce the change stimulus and processes that matter and are the vehicles that can actually deliver development. Consequently, problems as needs to be addressed are discernable or visible to the practitioner upfront out of cause and effect analysis. Solutions to the core problems analyzed can be posed as predetermined outcomes. This can be achieved through participatory processes in the planning phase to help get all stakeholders onboard, paving the way for ownership, building their capacity and gain the desired project sustainability. In using this theory, the study identified community capacity building as the problem that needs to be addressed to enhance the achievement of the desired project mandate. The following research questions were investigated:

1. To what extent has the top down organisational approach of capacity building influenced the sustainability of palliative care projects in Mayuge district?

2. To what extent has the bottom up organisational approach of capacity building influenced the sustainability of palliative care projects in Mayuge district?

3. To what extent has community organizing approach of capacity building influenced the sustainability of palliative care projects in Mayuge district?

Community capacity building approaches was the independent variable while project sustainability was the dependent variable. This relationship was explored using the following conceptual framework:-

\section{Community capacity building approaches (IV)}

Figure 1 show that the sustainability of palliative care 


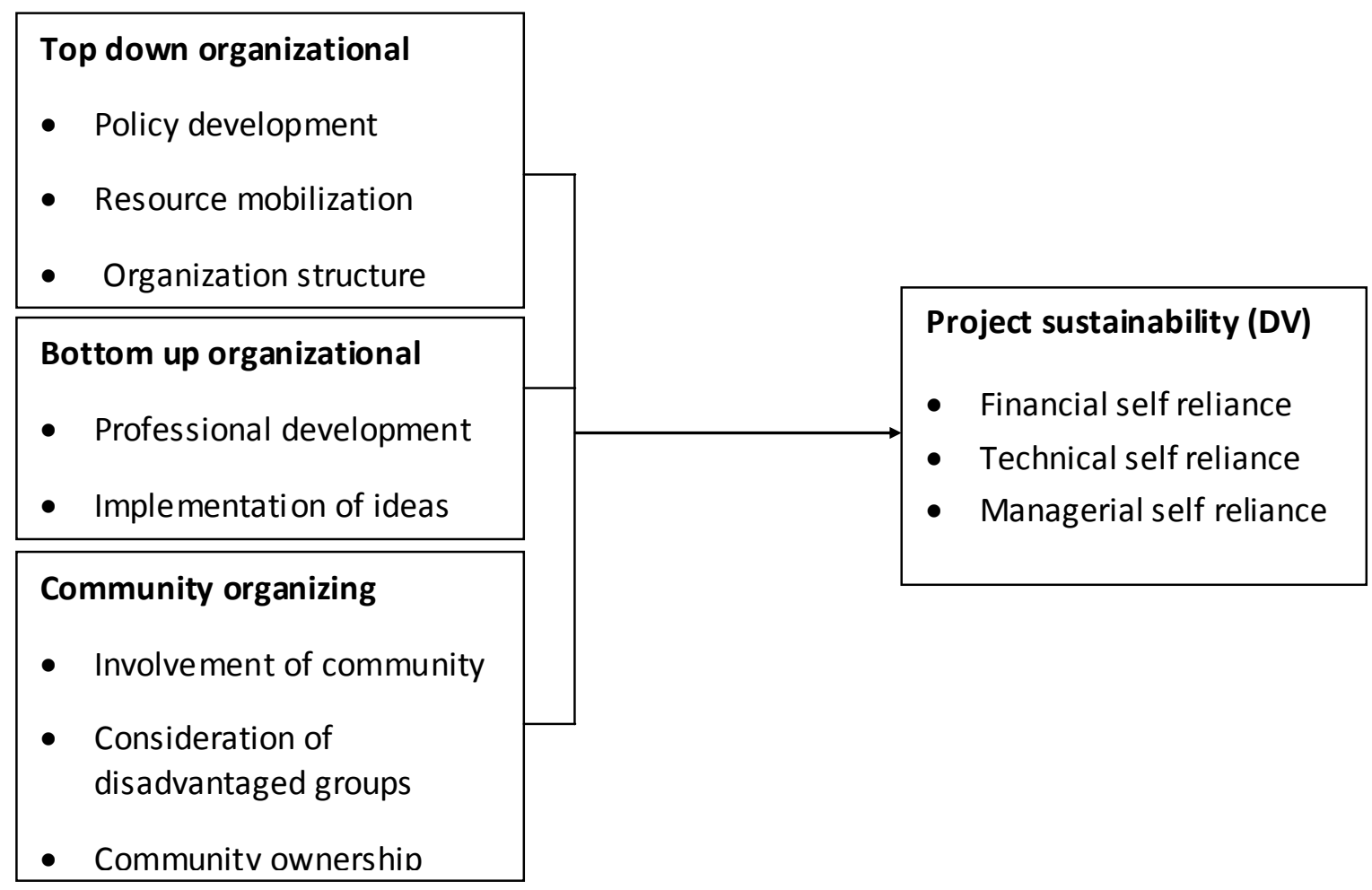

Figure 1. Model showing the relationship between capacity building and project sustainability. The model was adopted from the stakeholder's theory by Freeman (1984) and the Reeler (2006) social change theory.

projects depends on the capacity building approaches of top down organisational, bottom up organisational and community organization. Project sustainability has indicators of financial, technical and managerial self reliance thus a palliative care project will be assumed to be sustainable if it can by its self meet its financial, technical and managerial requirements. Top down organisational approach in capacity building involves efforts by the top management of the NGO to develop self sustaining policies, mobilizing resources, and putting in place an appropriate organisational structure to enhance project sustainability. Bottom up organisational approach on the other hand involve efforts directed to professional development and opportunity to implement learned knowledge and ideas from the professional development. Community organizing involves efforts directed to involvement of community leaders, considerations of disadvantage groups and community ownership during project implementation as key stakeholders to guarantee project success.

\section{METHODOLOGY}

The study used a cross-sectional design where both quantitative and qualitative approaches to assess the extent to which capacity building influenced the sustainability of palliative care projects were used. The cross-sectional survey method was used because it draws most of its data from the present, thus at that point in time and enables establishing the relationships between the variables (Amin, 2005). The study was carried out among the palliative care centers in Mayuge District on an accessible population of 150 respondents comprising of NGO officials, HCIV and HCIII palliative care personnel, district health team and patients on palliative care. These populations was considered because it is directly involved in the formulation and implementation of palliative care capacity building efforts and as beneficiaries and therefore possess considerable experiences in palliative care capacity building and sustainability of palliative care projects in the district.

The study selected up to 108 elements based on Krejcie and Morgan (1970) guidelines. The study used purposive sampling to select NGO personnel, health centre staff, and district health team who participated in capacity building and possess managerial experiences in the capacity building and sustainability of palliative care projects in the district. The study also used simple random sampling to select palliative care patients as beneficiaries of the palliative care interventions in the district. The validity of the instrument was tested using the Content Validity Index. This involved judges scoring the relevance of the questions in the instruments in relation to the study variables and a consensus judgment given on each variable taking only variables scoring above 0.70 accepted for social sciences. Top down organisational yielded a CVI of 0.75 bottom up yielded a CVI of 0.88 , community organizing yielded a CVI of 0.83 , while project sustainability yielded a CVI of 0.73 . Since all variable yielded a CVI above 0.70 accepted for social sciences (Amin, 2005) it was concluded that the 
instrument had a good validity in measuring the capacity building and sustainability of palliative care projects.

Reliability of a measure indicates the extent to which it is without bias and therefore ensures consistent measurement across time and across the various items in the statement suggesting that the finding would be consistently the same if the study was done over again (Mugenda and Mugenda, 1999). In this study a Cronbach's alpha coefficient was computed to show how reliable the data was using Software Package for Social Sciences (SPSS) taking only variables scoring above 0.70 accepted for social sciences and the results revealed that top down organisational approach to capacity building yielded Cronbach's alpha value of 0.75 , bottom up organizational yielded an alpha value of 0.81 , community organizing yielded an alpha value of 0.77 , while project sustainability yielded an alpha value of 0.74 . Since all variable yielded alpha values above 0.70 accepted for social sciences (Amin, 2005), it was concluded that the instrument was reliable in measuring capacity building approaches and sustainability of palliative care projects.

Quantitative data was presented in form of descriptive statistics using frequency and percentages for background information, mean and standard deviations for each of the variables used in the study, correlation and regression analyses. The correlation technique included Pearson's coefficient (+ or - to show the direction of the relationship between the variable) and significance tested at $99 \%$ and $95 \%$ confidence levels based on two tailed correlation and significant more than or equals to 0.05 . The regression analysis used the adjusted $R^{2}$ values, beta, $t$ values and significance values to determine the magnitude of the influence of the independent variables on the dependent variable (Amin, 2005).

\section{FINDINGS AND DISCUSSION}

\section{The sample characteristics}

The majority of respondents for the study who were 61 $(59.2 \%)$ were female while the male constituted 42 $(40.8 \%)$ a finding which suggested that the women were participating more in palliative care projects than their male counterparts either as patients, caretakers or palliative care health personnel. We infer that any efforts to enhance the sustainability of the palliative care projects in Mayuge district should consider the use of women as an entry point although the target should cover men. In terms of educational characteristics of our study respondents, 34 (33\%) had no formal education while $21.4 \%$ were diploma holders. Those who had attained a pos graduate education level constituted 13 (12.6\%) while $7(6.8 \%)$ had attained a post graduate education level. Those who had attained a certificate constituted 10 $(9.7 \%)$ while those who had attained a secondary level of education as their highest level of education constituted 9 $(8.7 \%)$ with the remaining $8(7.8 \%)$ covering those who had attained primary level of education. These findings suggested that the different palliative care stakeholders will need professional development to gain technical and managerial competencies as most of them had low education.

Analysis of the position of the respondent in relation to the palliative care project revealed that a total of 78
(75.7\%) were palliative care patients or caretakers, 11 $(10.7 \%)$ were palliative care personnel, $10(9.7 \%)$ were project staff while $4(3.9 \%)$ were from the district health team. These findings suggested that efforts was undertaken to collect data from the different stakeholders in the district and that capacity building efforts equally should target patients, care takers, palliative care health personnel, project staff and DHTs if the projects are to achieve the expected sustainability. A total of $46(44.7 \%)$ of the patients had been with the project for less than a year while $39(37.9 \%)$ had been with the project for 1 to 3 years. Those who had been with the project for 4-6 years constituted only $14(13.6 \%)$ while those who had been with the project for $7-9$ year constituted only $4(3.9 \%)$ of the total number of respondents. These study findings suggested that most stakeholders had been with the palliative care projects for a short time and needed training for enhanced project sustainability in the district.

\section{Sustainability of palliative care projects}

Sustainability of the palliative care projects according to the conceptual framework had three indicators of financial, technical and managerial self-reliance measured using 12 items scored on 5-point Likert Scale ranging from 5 = Strongly agree, $4=$ Agree, $3=$ Not sure, $2=$ Disagree, $5=$ Strongly disagree and the findings are shown in Table 1.

Table 1 reveals an aggregated mean of 2.32 which implied that the respondents disagreed to the majority of the questions suggesting a low level of the palliative care project sustainability in Mayuge district. The Standard deviation ranged between 0.61 and 1.21 , which was relatively narrow suggesting that the scores are very close to the mean. Item 5 which asked if the community people were capable of identifying community people in need of palliative care received the highest mean of 4.06 suggesting that the palliative care projects in Mayuge had enhanced the community people's technical capabilities to identify patients who may need palliative care intervention.

This position on sustainability of supported by one interviewee who when asked to comment on the status of palliative care projects had this to say:
"Right now the status is good because capacity was built for health workers to continue providing palliative care even after external support left".

\section{Another interviewee put it"}

"The palliative care project is doing well, especially with external support. The Hospice Jinja team does outreach and home visits in Mayuge Town Council, and Wabulungu, 
Table 1. Sustainability of the palliative care project in Mayuge district

\begin{tabular}{|c|c|c|}
\hline Scale & Mean & S.D \\
\hline \multicolumn{3}{|l|}{ Financial self-reliance } \\
\hline The community people can now adequately draw their own budgets for palliative care & 2.30 & 0.86 \\
\hline $\begin{array}{l}\text { The community people can now adequately mobilize their own financial resources for } \\
\text { palliative care }\end{array}$ & 2.07 & 1.09 \\
\hline $\begin{array}{l}\text { The community people can now adequately account for financial resources received } \\
\text { by the palliative care activities in their communities }\end{array}$ & 1.91 & 0.77 \\
\hline $\begin{array}{l}\text { The community people can now adequately prepare financial reports for the palliative } \\
\text { care funds received. }\end{array}$ & 2.14 & 0.95 \\
\hline \multicolumn{3}{|l|}{ Technical self-reliance } \\
\hline $\begin{array}{l}\text { The community people are capable of identifying community people in needs of } \\
\text { palliative care }\end{array}$ & 4.06 & 1.21 \\
\hline $\begin{array}{l}\text { The community people are capable of diagnosing palliative care patients without } \\
\text { external expertise }\end{array}$ & 2.25 & 0.75 \\
\hline $\begin{array}{l}\text { The community people are capable of prescribing palliative care for patients without } \\
\text { much external expertise }\end{array}$ & 2.19 & 0.73 \\
\hline $\begin{array}{l}\text { The community people are capable of making referrals for palliative care patients } \\
\text { without much external expertise }\end{array}$ & 2.45 & 0.93 \\
\hline \multicolumn{3}{|l|}{ Managerial self-reliance } \\
\hline The community people are capable of identifying palliative care needs & 2.06 & 0.61 \\
\hline The communities can design palliative care projects & 2.09 & 0.80 \\
\hline The communities can organize palliative care projects & 2.17 & 0.75 \\
\hline The communities can effectively control palliative care projects & 2.14 & 0.77 \\
\hline Overall Mean & 2.32 & \\
\hline
\end{tabular}

Source: Primary data

Magamaga areas. The Trained Palliative care personnel is doing a great work though with some limitations".

However, the interviewee responses seem to disagree with the quantitative finding especially item 3 which asked if the community people could adequately account for financial resources received by the palliative care activities in their communities received the lowest mean of 1.91 and item 9 which asked if the community people were capable of identifying palliative care needs in their communities also received a low mean of 2.06. Item 7 which asked if the community people were capable of prescribing palliative care for patients without much external expertise received the a low mean of 2.19 suggesting a low level of financial, technical and managerial self-reliance project sustainability expectations.

\section{How top down organizational approach of capacity building could influence the sustainability of palliative care projects}

Top down organisational was one of the dimensions of capacity building and had indicators of policy development, resource mobilization, and organizational structuring. These were measured using 12 items scored on 5 -point Likert Scale ranging from $5=$ Strongly agree, $4=$ Agree, 3 = Not sure, 2 = Disagree, 5 = Strongly disagree and the findings are shown in Table 2.

The study findings in Table 2 revealed that top down capacity building in the palliative care projects involved establishment of policy development by establishing a policy making arm of palliative care projects, establishment of a training and development policy, and documentation of palliative care proposals which act as the basis for implementing capacity building aimed at enhanced project sustainability.

Asked to describe the capacity building policy interventions at the policy level, one interviewee put it that:

"There are no new policies developed of recent. Palliative care project was implemented within the existing $\mathrm{MOH}$ and $\mathrm{WHO}$ policy standards in the provision of palliative care"

On organizational resources, the findings in table 1 
Table 2. Mean and Standard deviation results for Top down organisational approach

\begin{tabular}{|c|c|c|}
\hline Top down organizational & Mean & S.D \\
\hline \multicolumn{3}{|l|}{ Policy development } \\
\hline The palliative care projects have distinctive policy development organs & 4.17 & 1.27 \\
\hline The palliative care projects in Mayuge district have well established training and development policy & 4.18 & 1.22 \\
\hline $\begin{array}{l}\text { The palliative care projects have clearly documented project proposals which work as the mandate of the } \\
\text { project }\end{array}$ & 3.93 & 1.43 \\
\hline \multicolumn{3}{|l|}{ Resource mobilization } \\
\hline The palliative care project emphasized local human resource mobilization for administration of palliative care & 2.19 & 0.97 \\
\hline The palliative care project emphasized identification of local technical resource persons in palliative care & 2.26 & 0.94 \\
\hline $\begin{array}{l}\text { The palliative care project strived to mobilize adequate financial resources mobilization for palliative care } \\
\text { activities }\end{array}$ & 2.66 & 0.96 \\
\hline $\begin{array}{l}\text { The palliative care project emphasized mobilization of adequate transport facilities for the palliative care } \\
\text { activities in Mayuge district }\end{array}$ & 2.65 & 1.11 \\
\hline The palliative care project emphasized adequate palliative care medical equipments and suppliers mobilization & 2.97 & 1.84 \\
\hline \multicolumn{3}{|l|}{ Organization structure } \\
\hline The palliative care projects $\mathrm{i}$ & 4.11 & 1.23 \\
\hline Palliative care projects in Mayuge district have clearly established project/matrix based structures & 2.12 & 1.11 \\
\hline There is clear separation of power and authority among project staff & 4.15 & 1.23 \\
\hline There clear procedures and rules for use in palliative care & 4.24 & 1.20 \\
\hline Overall mean & 3.3025 & \\
\hline
\end{tabular}

Source: Primary data

revealed inadequate identification of local human, financial, equipment and material resources necessary as inputs for effective project implementation which ultimately constrains project sustainability due to lack of these vital resources necessary to facilitate project activities.

Asked to describe the resource mobilization for palliative care, one interviewee had this to say:

"DHT members and health facility staff were oriented on making priorities to palliative care services especially in requesting for drugs and mentoring/coaching. This was followed up and these activities were incorporated in the department work-plan"

On organisational structure, the results in Table 2 further suggested that although efforts was undertaken to identify and structure palliative care organisational structure based on functional area, separation of powers and authority, establishment of procedures and rules; the failure to adopt matrix or project organisational structures requiring some project implementers to report to more than one functional supervisor adversely affects project implementation due to lack effective coordination of activities.

In an interview on project organisational structuring one interviewee informed the study that:

"Capacity was built to have quality improvement teams for palliative care right from the district to the health facilities. These met on a monthly basis to plan for palliative care services. At community level another structure was established to identify and refer patients for palliative care services"

Another interviewee put it that:

"The district has recognized the need for a Palliative care focal person who is doing this role. We hope more structures will be put in place."

These finding are supported by the use of top-down organizational approach which states that building and sustaining capacity requires organizational capacity as well as the expertise of individuals through creation of an enabling policy making mechanism (Grisso et al., 1995; Rist, 1995). There is also a commonly held view that coordination and planning are often necessary to ensure resources, such as personnel, equipment and facilities can be mobilized when required (Poncelot and de Ville de Goyet, 1996). The need to effectively structure 
Table 3. Mean and Standard Deviation results for Bottom up organizational

\begin{tabular}{lcc}
\hline Bottom up & Mean & S.D \\
\hline Professional development & 2.34 & 0.81 \\
Palliative care staff training needs are regularly identified & 2.36 & 0.78 \\
Palliative care staff regularly undergo off-the-job training to develop technical expertise in palliative care & 2.41 & 0.82 \\
Palliative care staff regularly undergo on-the-job training to develop technical expertise in palliative care & 3.80 & 1.27 \\
The palliative care project emphasizes identification of community stakeholders to be trained to develop & 2.34 & 0.81 \\
technical expertise & \\
$\quad$ Community stakeholders are regularly trained in palliative care management to develop technical expertise & \\
Implementation of ideas & 2.24 & 0.85 \\
$\quad$ The palliative care projects in Mayuge solicits for ideas from district stakeholders for enhancing community & 2.34 & 0.80 \\
capacity in palliative care & 2.32 & 0.82 \\
$\quad$ The palliative care projects in Mayuge solicits for ideas from beneficiary communities for enhancing & 2.27 \\
community capacity in palliative care & \\
$\quad$ Ideas generated by the stakeholders are implemented by the palliative care projects & \\
Overall mean &
\end{tabular}

Source: Primary data

organizations based on the matrix structure which is functional is supported by previous position that in some cases, increased capacity may be acquired through organizational restructuring and partnerships between organizations or groups of people who might otherwise have little or no working relationship as another approach to building capacity (Chavis, 1995; Marty et al., 1996).

\section{How bottom up organisational approach of capacity building influence the sustainability of palliative care projects}

Bottom up organisational three indicators of professional development and implementation of project stakeholders' ideas measured using 8 items scored on 5-point Likert Scale ranging from $5=$ Strongly agree, $4=$ Agree, $3=$ Not sure, 2 = Disagree, 5 = Strongly disagree and the findings are shown in Table 3.

The findings on professional development as shown in Table 3 revealed that although there was effort to establish professional development through identification of the community stakeholders for training, the failure to adequately and continuously identify training needs and designing of appropriate training on the job and off the job training programs was indicative of inadequate professional development in the capacity building practices which constrained the implementation of the palliative care projects in the district.

Asked to describe the professional development efforts in building capacity for the palliative care projects, one interviewee was in the affirmative:

\section{DHT members were trained in palliative care.}

\begin{abstract}
These with the support of external expertise trained health workers at health facilities to offer palliative care services. Health facility workers continued to have CMEs on palliative care at facility level and occasionally collaborative meetings with other health workers offering palliative care services from Namutumba district were held. I recommend that palliative care services should be strongly emphasized and incorporated in basic training for health workers so that it is not treated as a special service.
\end{abstract}

However, another interviewee noted that:

Latest reports from the district palliative care focal person do not indicate of any new personnel sent for Palliative care training. The challenge is sustaining what was started. Training of only one personnel in the whole district may not serve the purpose of integrating the program across the whole district.

On implementation of ideas, findings in Table 3 above, revealed inadequate management of the stakeholders idea generation and implementation which constraints the community ownership of the project interventions as the ideas may not necessarily be relevance and responsive to the community needs. The management of the palliative care projects will therefore need to adequately generate ideas from the district authorities, beneficiaries and ensure idea consideration in the palliative care project implementations for enhanced project sustainability.

These study findings and observations on bottom up 
Table 4. Mean and Standard Deviation Results for Community Organizing

\begin{tabular}{|c|c|c|}
\hline Community organizing & Mean & S.D \\
\hline \multicolumn{3}{|l|}{ Involvement of community } \\
\hline The palliative care projects in Mayuge have considered the involvement of key community leaders & 4.07 & 1.23 \\
\hline The palliative care projects in Mayuge emphasize community outreach of their activities & 2.34 & 0.99 \\
\hline $\begin{array}{l}\text { The palliative care projects in Mayuge emphasize collaborations and information sharing with other stakeholders in } \\
\text { the community }\end{array}$ & 4.04 & 1.20 \\
\hline \multicolumn{3}{|l|}{ Consideration of disadvantaged groups } \\
\hline The palliative care projects in Mayuge have considered the involvement of women groups & 2.21 & 0.74 \\
\hline The palliative care projects in Mayuge have considered the involvement of youth groups & 2.34 & 0.69 \\
\hline The palliative care projects in Mayuge have considered the involvement of elderly persons & 2.34 & 0.68 \\
\hline The palliative care projects in Mayuge have considered the involvement of people with disabilities & 2.40 & 0.69 \\
\hline \multicolumn{3}{|l|}{ Community ownership } \\
\hline The palliative care projects in Mayuge districts are oriented towards the local community people & 4.02 & 0.84 \\
\hline Community people were sensitized on the palliative care projects in their communities & 2.13 & 0.68 \\
\hline There is an effort to involve community members in palliative care project planning & 2.17 & 0.76 \\
\hline There is an effort to involve community members in palliative care project implementation & 2.18 & 0.74 \\
\hline There is an effort to involve community members in palliative care project monitoring and evaluation & 2.99 & 1.08 \\
\hline Overall mean & 2.46 & \\
\hline
\end{tabular}

Source: Primary data

are supported by the view that while capacity building may involve further training in a specialization (Chalmers, 1997; Hawe et al., 2009), broadening the skills of generalist workers can also have strategic benefits. This approach according to Crisp et al., (2000) focuses on training members of the organization and providing them with skills and knowledge which is not only beneficial to the individuals concerned but more importantly to the organization and the wider community.

\section{How community organizing approach of capacity building influence the sustainability of palliative care projects}

Community organizing was conceptualized to include indicators of community involvement, consideration of disadvantaged groups and community ownership measured using 12 items and the findings are shown in Table 4 below.

Findings in Table 4 show that a reasonable level of involvement of community is evident in efforts by the palliative care in the implementation of project activities although the project were still constrained with full board implementation of community outreach programs targets. It was therefore necessary to build capacity for enhanced community outreach in the project areas.

In an interview on the efforts to involve communities, one interviewee observed that:

\begin{abstract}
"Communities were sensitized on palliative care and afterwards they identified Community Health workers who were trained in palliative care so that they could assist in identifying and referring patients who need palliative care services at community level".
\end{abstract}

In line with the above, another interviewee put it that:

"The volunteers trained are active especially that one of Wabulungu- Ayazika, she is great. I don't know if others too are doing any help in Palliative care"

On consideration of disadvantaged groups, results shown in Table 4 above revealed that by design and implementation of palliative care project implementation, there was less consideration of disadvantaged or special groups such as women, youth, elderly and disabled people. The management of the palliative care projects needed to consider these disadvantaged groups in their community organizing approach to enhance project sustainability.

One interviewee accepts the failure to consider disadvantaged groups and put it that:

"No special consideration was given to disadvantaged groups but the palliative projects in the district does not discriminate on the basis 
Table 5. Summary of correlation analysis between capacity building approaches and project sustainability

\begin{tabular}{|c|c|c|c|c|c|}
\hline Variable & & 1 & 2 & 3 & 4 \\
\hline \multirow{2}{*}{ Top Down Organisational } & Pearson Correlation & 1 & - & - & - \\
\hline & Sig. (2-tailed) & - & - & - & - \\
\hline \multirow{2}{*}{ Bottom Up Organisational } & Pearson Correlation & $.379^{* *}$ & 1 & - & - \\
\hline & Sig. (2-tailed) & .000 & - & - & - \\
\hline \multirow{2}{*}{ Community Organizing } & Pearson Correlation & $.471^{* *}$ & $.511^{\star *}$ & 1 & - \\
\hline & Sig. (2-tailed) & .000 & .000 & - & - \\
\hline \multirow{2}{*}{ Project Sustainability } & Pearson Correlation & $.492^{\star *}$ & $.514^{\star \star}$ & $.759^{* *}$ & 1 \\
\hline & Sig. (2-tailed) & .000 & .000 & .000 & - \\
\hline \multicolumn{6}{|c|}{ **. Correlation is significant at the 0.01 level (2-tailed). } \\
\hline
\end{tabular}

$\mathrm{P} \leq 0.05$

\section{of being disadvantaged".}

The other interviewee acknowledges the failure to consider disadvantages groups and put it that:

"Palliative care services aren't discriminative and hence all who need the service get it".

On community ownerships, Table 4 above shows that although the palliative care projects were oriented to the communities, the lack of community sensitization, lack of community participation in the planning and implementation of palliative care projects constrained the effective development of community ownership of the projects. The management of the palliative care projects therefore will need to continuously sensitize, involve community people in the planning and implementation of palliative care projects.

To verify the above study quantitative findings, we interviewed on respondent on the issue of focusing on community ownership of palliative care projects and had this to say:

\section{"During sensitization, communities were made to understand that community health workers identified by the community were solely volunteers and belonged to the community".}

These study findings and position on community organizing are supported by the view that in involvement of community stakeholders, Chavis (1995); Marty et al., (1996) noted that development of partnerships between organizations or groups of people who might otherwise have little or no working relationship is another approach to building capacity. The assumption is that providing possibilities for the two-way flow of knowledge can lead to partnerships through which the resources required to plan and implement programs may emerge. This is especially so if prominent members of the community, including community leaders, community advocates and representatives are involved (Wickizer et al., 1998).

\section{Correlation and regression results}

To test the relationship between top down, bottom up, community organizing approaches of capacity building and sustainability of palliatives care projects Pearson's correlation statistics was conducted and the findings are presented in Table 5.

Table 5 shows Pearson's correlation coefficient $r=$ $0.492^{* *}$ and $p=0.000$ between top down organisational and palliative care project sustainability suggesting that there was a high positive significant relationship between top down organisational and the sustainability the palliative care projects in Mayuge district. Similarly, Table 5 above shows Pearson's correlation coefficient $r=$ $0.514^{* *}$ and $p=0.000$ between bottom up organisational and palliative care project sustainability suggesting that there was high positive significant relationship between the bottom up organisational approach to capacity building and the sustainability the palliative care projects in Mayuge district. Furthermore, Pearson's correlation coefficient $r=0.759^{* *}$ and $p=0.000$ between community organizing and palliative care project sustainability suggesting that there was high positive significant relationship between community organizing approach to capacity building and the sustainability of palliative care projects in Mayuge district. This had project management policy implication in that improved capacity building approaches of top down, bottom up and community organizing had a resultant effect of improving the 
Table 6. Multiple regression results between top down, bottom up organisational, Community organizing and Project sustainability

\begin{tabular}{lccccc}
\hline Adjusted $\mathbf{R}^{2}=\mathbf{0 . 6 0 3}$ & \multicolumn{7}{l}{} \\
\hline \multirow{2}{*}{ Model } & \multicolumn{2}{l}{ Unstandardized coefficients } & Standardized coefficients & \multirow{2}{*}{$\mathbf{t}$} & \multirow{2}{*}{ Sig. } \\
\cline { 2 - 5 } & $\mathbf{B}$ & Std. Error & Beta $\boldsymbol{\beta}$ & & \\
\hline (Constant) & .363 & .160 & & 2.262 & .026 \\
Top Down organisational & .086 & .042 & .146 & 2.035 & .045 \\
Bottom Up organisational & .105 & .054 & .143 & 1.939 & .05 \\
Community Organizing & .554 & .070 & .617 & 7.967 & .000 \\
\hline
\end{tabular}

a. Predictors: (Constant), Community Organizing, Top Down Organisational , Bottom Up Organisational b. Dependent Variable: Project Sustainability

$P \leq 0.05$

sustainability of palliative care projects in Uganda. A multiple regression was also conducted to establish the extent to which the capacity building dimensions of top down organisational, bottom up organisational and community organizing influenced the sustainability the palliative care projects and the findings are shown below in Table 6.

Table 6 shows an adjusted $R^{2}$ value of 0.603 between capacity building dimensions top down, bottom up organisational, community organizing and project sustainability suggesting that the capacity building dimensions predicted $60.3 \%$ of the variance in palliative care project sustainability while other variable predicted the remaining $39.7 \%$ of the variance in the palliative care project sustainability. The community organizing capacity building approach had the highest influence on the sustainability of the palliative care projects $(\beta=0.617, t=7.967$, and significance 0.000 ). This was followed by Top down organisational approach to capacity building $(\beta=1.46, t$ $=2.035$, and significance 0.045). Bottom up approach although small in influence, it was a significant predictor of the variance in project sustainability of the palliative care projects $(\beta=0.143, t=1.939$, and significance 0.05). This study therefore inferred that efforts to enhance palliative care projects should give priority of community organizing aspects of capacity building. These should be followed by the use of top down organizational and bottom up organisational approaches.

These study finding on the extent to which capacity building dimensions of top down, bottom up and community organizing influenced project sustainability are supported by other previous scholars such as Bainson (1994) whose study on the Ghana Leprosy Service observed that a more responsive and effective health agency gained from devolving the planning and implementation of programs from a single central agency to a regional or district level was important for sustainability of integrated primary health care programs at a district level. In support, Kleemeier (2000) study on Malawian rural piped water project found that half the schemes were performing poorly attributed largely to weak institutional support after external agencies had withdrawn their support.

Focusing on capabilities as critical success factors offers relevant generic functional capabilities related to coordinated intergovernmental organization, national, and civil society actions. This enhances capacity building to include common assessments of specific desired interventions at the national, regional, and global geopolitical levels, so as to create locally-tailored interventions and increased cooperative efforts. It has also been noted that while capacity building may involve further training in a specialization (Chalmers, 1997), broadening the skills of generalist workers can also have strategic benefits of enhancing community self reliance (Poncelot and de Ville de Goyet, 1996).

Other scholars have noted that underpinning the community involvement approach is the notion that the most successful programs are those which are initiated and run by the members of the local community (de Graaf, 1986; Eisen, 1994). Nevertheless, the approach to capacity building is most likely to be effective in communities with existing resources, for example, health and welfare professionals, who become involved with health promotion (Goodman et al., 1993). This study therefore inferred that palliative care projects in the Uganda will be enhanced with the use of effective top down, bottom up and community organizing approaches to capacity building.

\section{CONCLUSION AND POLICY IMPLICATIONS}

The study concluded that the financial, technical and managerial self-reliance aspects of project sustainability significantly depends on the efforts by the management of the NGO to build capacity through developing selfsustainability policies, adequate mobilization of local human and non-human resources, and putting in place an appropriate matrix organisational structures. Secondly 
the study inferred that the financial, technical and managerial self-reliance aspects of project sustainability significantly depend on the efforts by the management of the NGO to build capacity through professional development by identifying community stakeholders training needs, development of appropriate on the job and off the job training programs and to implementation of local/community learned knowledge and ideas from the professional development. Lastly, the study concluded that the financial, technical and managerial self-reliance aspects of project sustainability significantly depend on the efforts by the management of the NGO to build capacity through involvement of community leader; consideration of disadvantaged groups such as women, youth, elderly and disabled persons; and focusing on community ownership of the project.

One of the palliative care project management implications derived from this study was that to enhance project sustainability, the management of palliative care projects/NGOs should ensure adequate identification of local human, financial, equipment and material resources. This should be complemented with redesigning and adoption of matrix or project organisational structures requiring some project implementers to report to more than one functional supervisor. To enhance project sustainability, the management of palliative care projects/ NGOs should adequately and continuously identify training needs and design appropriate training on the job and off the job training programs such as internship, coaching, mentoring, apprenticeship, continuous professsional development and short course training courses. This should be complemented with solicitation and implementation of district authorities' and beneficiaries' ideas on palliative care through use of project idea generation meetings or workshops. The other palliative care project management implication was that to enhance palliative care project sustainability the management of palliative care projects/NGOs should involve community people in the planning and implementation of palliative care projects, implementation of community outreach programs through location of palliative care centre within a $5 \mathrm{~km}$ range, use of mobile palliative care services and home care services at a reasonable cost to the patients who may need home care services. The above efforts should be complemented with creation of partnerships with local and national groups working for the betterment of disadvantaged or special groups such as women, youth, elderly and disabled people.

\section{REFERENCES}

Amin EM (2005). Social Science Research:Conception, Methodology and Analysis, Makerere University Press. Kampala

Baillie E (2008). A capacity-building conceptual framework for public health nutrition Practice. Public Health Nutr. 22: 1-8. Available online at doi:10.1017/S1368980008003078
Bainson KA (1994). Integrating leprosy control into primary health care: The experience in Ghana. Leprosy Rev. 65(4):376-384.

Brown L (1997). Who Changes? Institutionalizing Participation in Development. London: Intermediate Technology Publications, Ltd. [CB, CS, PART] 3

Chambers R (1994). Participatory Rural Appraisal (PRA): Analysis of Experience. World. Develop. 22(9): 1253-1268

Chalmers B (1997). Childbirth in Eastern Europe.Midwifery.13 (1): 2-8.

Chavis D (1995). Building community capacity to prevent violence through coalitions and partnerships. J.Health Care Poor and Underserved, 6 (2): 234-245.

Crisp B, Swerissen H, Duckett S (2000). Four approaches to capacity building in health:consequences for measurement and accountability. Health Promotion Int. 15 (2): 99-107

Cooper L, Verity F, Bull M (2005).Good practices and pitfalls in community-based capacity building and early intervention projects: a toolkit. Canberra: Commonwealth of Australia

Deborah E (2005). Capacity-building: an approach to people centered development. UK and Ireland: Oxfam UK and Ireland pp.30-39

Graaf M (1986). Catching fish or liberating man: social development in Zimbabwe. J. Soc. Dev. Africa 1(7):26.

Eisen A (1994). Survey of neighborhood-based, comprehensive community empowerment initiatives. H. Educ. Quart.21:235-252

Diane S (2004). Transfer Agents and Global Networks in the 'Transnationalisation' of Policy. J. Eur. Public Policy 11(3): pp545-66.

Freeman RE (1984). "Strategic Management: A stakeholder Approach". Boston, MA: Pitman.

Grisso JA, Christakis E and Berlin M (1995). Development of a clinical research program in women's health. J. Women's Health 1(2):169178

Goodman R, Steckler, A, Hoover S, Schwartz R (1993). A critique of contemporary community health promotion approaches based on a qualitative review of six programs in Maine. Am. J. Health Promot. 7(3):208-221.

Haddad EF, Zoubi Rania AEM, Shraideh F (2007). MEDA WATER: Int. Conference on sustainable water management. 21-24 March 2007, Tunis, Tunisia.

Hawe P, Shiell A, Riley T (2009). Theorising Interventions as Events in Systems. Published online: on 24 April 2009. Am J Community Psychol. 43:267-276 Available at DOI 10.1007/s10464-009-9229-9

Jones T, Wick A (1999). Convergent Stakeholder Theory. A. Manage Rev. 24(2):206-221.

Kaplan A (2000). Capacity Building: Shifting the Paradigms of Practice. Dev. Pract. 10 (3\&4):517-526.

Kleemeier $E(2000)$. The Impact of Participation on Sustainability: An Analysis of the Malawi Rural Piped Scheme Program. World Dev. 28(5):929-944

Krejcie RV, Morgan DW (1970). Determining Sample Size for Research Activities, Educational and Psychological Measure 30(3):607-610.

Marty PJ Hefelfinger J, Bacon-Pituch B (1996). Florida tobacco prevention and control program: building capacity through collaboration. J. Florida Med. Assoc. 83:117-121. Avaiable online at: DOI: 10.1146/annurev.pu.17.050196.002005.

Palliative Care Association of Uganda Report http://hospiceafrica.merseyside.org/HAU\%20Report\%202012\%20FINAL.pdf

Poncelot JL, de Ville de Goyet C (1996). Disaster preparedness: institutional capacity building in the Americas. World Health Stat. Q. 49(3-4):195-198.

Reeler D (2006).A Theory of Social Change and Implications for Practice, Planning, Monitoringand Evaluation, CDRA, 2006.

Rist RC (1995). Postscript: development questions and evaluation answers. New Directions Evaluation 67:167-174.

Smillie I (2001).Patronage or Partnership: Local Capacity Building in a Humanitarian Crisis. Bloomfield, CT: Kumarian Press. Bloomfield, USA.

Uganda NGO Forum (2008).providing a sharing and reflection platform for NGOs to influence governance and development processes in Uganda, and enhance their operating environment, Organisational Strategy 2008/9 - 2011/12.

UNAIDS (2010).AIDS Epidemic Update. Geneva: UNAIDS. 
Afr. J. Bus. Manage.

Wickizer T M, Wagner E and Cheadle A (1998). Implementation of the Henry J. Kaiser family foundation's community health promotion grant program: A process evaluation. Milbank Quarter. 76(1): 121-147 